\title{
Tracheal Extubation
}

\author{
Carlos A Artime MD and Carin A Hagberg MD
}

\author{
Introduction \\ Extubation Failure \\ Risk Factors for Extubation Failure \\ Causes of Extubation Failure \\ Laryngospasm \\ Postobstructive Pulmonary Edema \\ Vocal Cord Dysfunction \\ Laryngeal Edema \\ Residual Neuromuscular Blockade \\ Preventing Extubation Failure \\ Weaning From Mechanical Ventilation \\ Decision to Extubate \\ Extubation After Elective Intubation \\ Extubation of the Difficult Airway \\ Extubation Strategies \\ Airway Exchange Catheter-Assisted Extubation \\ Laryngeal Mask Airway-Assisted Extubation \\ Remifentanil Extubation Technique \\ Treatment of Extubation Failure \\ Unplanned Extubation \\ Future Research \\ Conclusions
}

\begin{abstract}
Tracheal extubation in both the critical care and anesthesia setting is not only an important milestone for patient recovery, but also a procedure that carries a considerable risk of complication or failure. Mechanical ventilation is associated with significant complications that are time-dependent in nature, with a longer duration of intubation resulting in a higher incidence of complications, including ventilator-associated pneumonia, and increased mortality. Extubation failure and subsequent re-intubation are associated with an overall increase in the duration of mechanical ventilation, increased mortality, a greater need for tracheostomy, and higher medical costs. These risks demand that the process of extubation be managed by practitioners with a detailed understanding of the causes of extubation failure and the potential complications. A pre-established extubation plan with considerations made for the possible need for re-intubation is of the utmost importance. Key words: airway exchange catheters; airway management; difficult airway; extubation; laryngeal mask airway; ventilator weaning; noninvasive ventilation. [Respir Care 2014;59(6):991-1005. @ 2014 Daedalus Enterprises]
\end{abstract}

The authors are affiliated with the Department of Anesthesiology, The University of Texas Medical School at Houston, Houston, Texas.

Dr Hagberg presented a version of this paper at the 52nd RESPIRATORY
CARE Journal Conference, "Adult Artificial Airways and Airway Adjuncts," held June 14 and 15, 2013, in St Petersburg, Florida.

Dr Artime served on the speakers bureau and as an unpaid consultant for 


\section{Tracheal Extubation}

\section{Introduction}

Tracheal extubation in either the critical care or anesthesia setting is not only an important milestone for patient recovery, but also a procedure that carries a considerable risk of complication or failure. Mechanical ventilation is associated with significant complications that are timedependent in nature, with a longer duration of intubation resulting in a higher incidence of complications, including ventilator-associated pneumonia (VAP), and increased mortality. ${ }^{1}$ Extubation is beneficial in that it eliminates the work of breathing imposed by the endotracheal tube (ETT), lowers the risk for VAP, improves patient comfort, and improves airway clearance by allowing for an effective cough. ${ }^{2}$ However, extubation failure and subsequent reintubation are associated with an overall increase in the duration of mechanical ventilation, increased mortality, a greater need for tracheostomy, and higher medical costs. ${ }^{3}$

Analysis of the American Society of Anesthesiologists (ASA) Closed Claims database has demonstrated that although outcomes related to airway complications at the time of intubation have been improving over the last $20 \mathrm{y}$, the same does not hold true for extubation. ${ }^{4}$ Airway management complications at extubation are not confined to the United States. As was made evident in the recent Fourth National Audit Project (NAP4) of the Royal College of Anesthetists in the United Kingdom, one third of major complications of airway management occurred at extubation or in the recovery room, with a mortality rate of $5 \% .^{5}$ Data such as these have led to increased recognition for the need to develop strategies for safe and successful extubation. As such, the Difficult Airway Society (DAS) recently published the first comprehensive guidelines for management of tracheal extubation in adult perioperative practice. ${ }^{6}$ Although not explicitly focused on extubation in the ICU, the principles outlined in the guidelines are applicable to extubation in all settings.

\section{Extubation Failure}

Successful extubation is dependent on two factors: the ability to tolerate spontaneous breathing without mechanical ventilatory support and the ability to maintain a patent

\footnotetext{
Mylan Pharmaceuticals and received research support from Cadence Pharmaceuticals. Dr Hagberg served as an unpaid consultant for Ambu A/S and received research support from Ambu, Cadence Pharmaceuticals, Karl Storz Endoscopy, and King Systems.
}

Correspondence: Carlos A Artime MD, Department of Anesthesiology, The University of Texas Medical School at Houston, 6431 Fannin Street, MSB 5.020, Houston, TX 77030. E-mail: carlos.artime@uth.tmc.edu.

DOI: $10.4187 /$ respcare.02926 airway once the ETT is removed.7,8 Extubation failure is often defined as the need for re-intubation within $24-72 \mathrm{~h}$ of a planned extubation ${ }^{8}$; however, this definition does not differentiate between the two primary types of failure. Increasingly, therefore, the term extubation failure has been used to refer to "the inability to tolerate removal of the translaryngeal tube, ${ }^{\prime} 7,8$ whereas weaning or liberation failure is used to refer to the inability to tolerate spontaneous ventilation without mechanical support. ${ }^{7,9}$

The incidences of extubation and liberation failure vary depending on both the clinical setting and patient factors. In general, re-intubation is relatively uncommon after general anesthesia for elective surgery, with reported rates of $0.1-0.45 \% .^{7}$ The most common causes for re-intubation include respiratory insufficiency, airway obstruction, bronchospasm, residual neuromuscular blockade, residual effects of sedatives/opioids, and aggressive fluid administration. ${ }^{7}$ In the ICU, where patients are mechanically ventilated as they recover from acute respiratory failure, re-intubation is predictably more common, with rates of 2-25\%.9 Extubation and liberation failure are frequently linked in the ICU population ${ }^{7}$ and can be a result of upper airway obstruction, excess secretions, inability to protect the airway, concomitant failure of other organ systems, or an imbalance between the work of breathing and respiratory muscle capacity. ${ }^{9}$ Both in the ICU and after anesthesia, re-intubation after extubation failure usually occurs within $2 \mathrm{~h}$ of extubation and rarely after $24 \mathrm{~h} .^{7}$

Data from the ASA Closed Claims Project and NAP4 indicate that although extubation failure in the immediate postoperative period is rare, especially for elective surgery, the implications are grave, with higher rates of death and brain damage than during other phases of anesthesia. $4,5,7$ The NAP4 report showed a mortality rate of 5\% and a rate of $13 \%$ for severe outcomes with extubation failure related to general anesthesia. ${ }^{5}$ Likewise, in the critical care setting, a need for re-intubation is associated with an increased duration of mechanical ventilation and increased mortality (as high as 50\%). ${ }^{8,10}$ Although some of this association may be explained by the fact that patients who require re-intubation are more likely to have comorbid conditions that independently increase the risk of mortality, most studies that adjust for severity of illness and incidence of comorbidities show an independent association between extubation failure and mortality.9,11 This may be explained partly by the adverse outcomes associated with prolonged mechanical ventilation; however, a recent study by Thille et $\mathrm{al}^{10}$ suggests that failed extubation or unplanned extubation is directly linked to a clinical deterioration that might explain the increase in mortality. Evidence suggests that re-intubation due to liberation failure is associated with worse outcomes and higher mortality than re-intubation due to extubation failure. ${ }^{7}$ 


\section{Tracheal Extubation}

Table 1. Airway Risk Factors From the Difficult Airway Society Guidelines for Management of Tracheal Extubation

\begin{tabular}{l}
\hline \hline Pre-existing airway difficulties \\
Difficult mask ventilation at induction \\
Difficult tracheal intubation at induction \\
History of difficult airway management \\
Obesity/obstructive sleep apnea \\
Increased risk for aspiration of gastric contents \\
Perioperative airway deterioration \\
Surgical factors (anatomical distortion, hemorrhage, hematoma, \\
edema) \\
Nonsurgical factors (dependent edema due to positioning, airway \\
trauma from prior airway management, aggressive fluid \\
management) \\
Restricted airway access \\
Halo fixation \\
Mandibulomaxillary fixation \\
Surgical implants \\
Cervical collar \\
Large head/neck dressings
\end{tabular}

Adapted from Reference 6.

The concept of an optimal rate of re-intubation in the critical care setting has been proposed. Very low rates of re-intubation suggest that mechanical ventilation is being continued for an unnecessarily long time, whereas very high rates indicate that too many patients are extubated prematurely. This optimal rate of re-intubation is suggested to be in the range of $5-15 \% .10,12$

\section{Risk Factors for Extubation Failure}

In the perioperative setting, a number of factors that increase the risk of extubation failure have been identified. The ASA Closed Claims analysis demonstrated that problems at extubation were more common in patients with obesity or obstructive sleep apnea (OSA). ${ }^{4}$ Likewise, in the NAP4 report, the most common comorbidities associated with re-intubation after anesthesia included obesity (46\%), COPD (34\%), and OSA (13\%). ${ }^{5}$ The DAS extubation guidelines consider the presence of pre-existing airway difficulties (eg, difficult initial airway management, obesity/OSA, and elevated risk for aspiration of gastric contents), perioperative airway deterioration (anatomical distortion, edema, or hemorrhage due to surgical or nonsurgical factors), and/or restricted airway access as risk factors for extubation failure (Table 1). ${ }^{6}$

Factors associated with an increased risk of extubation failure in the ICU include advanced age, prolonged duration of mechanical ventilation, anemia, higher severity of illness, use of continuous intravenous sedation, need for transportation outside of the ICU, and unplanned extubation (Table 2). ${ }^{9}$ Medical and multidisciplinary patients are
Table 2. Factors Associated With Increased Risk of Extubation Failure

Advanced age $(>70 \mathrm{y})$

Duration of ventilation before extubation

Anemia (hemoglobin $<10 \mathrm{~g} / \mathrm{dL}$, hematocrit $<30$ )

Severity of illness at time of extubation

Semirecumbent positioning after extubation

Use of continuous intravenous sedation

Need for transportation outside the ICU

Unplanned extubations

Adapted from Reference 9.

Table 3. Medical Conditions Associated With Increased Risk of Extubation Failure

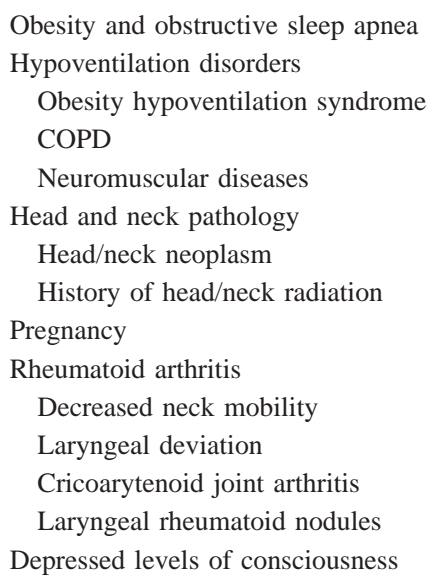

Adapted from Reference 7.

at higher risk for extubation failure than surgical patients. ${ }^{8}$ In neurosurgical patients, a Glasgow coma score of $<8$ has also been shown to be predictive of extubation failure. ${ }^{13}$

Regardless of the setting, certain coexisting medical conditions may lead to difficulty at the time of extubation, including rheumatoid arthritis, OSA, hypoventilation disorders, neuromuscular conditions, and depressed levels of consciousness (Table 3). General risk factors such as impaired respiratory or cardiovascular function, neuromuscular impairment, hypothermia, hyperthermia, and metabolic derangements can also complicate extubation. ${ }^{6}$

\section{Causes of Extubation Failure}

Extubation failure is often caused by mechanisms that affect upper airway patency, including laryngospasm, vocal cord dysfunction, laryngeal edema, airway trauma, and pharyngeal obstruction. In cases of severe upper airway obstruction, negative-pressure pulmonary edema can de- 
velop, requiring re-intubation. Other causes include excess respiratory secretions, inability to protect the airway, cardiac failure or ischemia, encephalopathy, residual effects of neuromuscular blockade or sedative medications, and aspiration. ${ }^{9}$ Weaning failure that was not present or recognized before extubation can also present as extubation failure. ${ }^{9}$

\section{Laryngospasm}

Laryngospasm is a common cause of upper airway obstruction after extubation that can lead to extubation failure. It is an exaggerated, maladaptive manifestation of the protective glottic closure reflex. It is usually provoked by glossopharyngeal or vagal stimulation due to airway instrumentation or vocal cord irritation (eg, from blood or vomitus), but can be precipitated by other noxious stimuli and can persist well after removal of the stimulus. Treatment of laryngospasm includes removal of airway irritants and, if needed, administration of a small dose $(20 \mathrm{mg}$ for an adult) of succinylcholine followed by re-intubation. ${ }^{14}$ CPAP with $100 \%$ oxygen is commonly cited as a therapeutic maneuver, although this may push the aryepiglottic folds closer together and may actually promote laryngospasm by acting as a mechanical stimulus. ${ }^{15}$ Bilateral pressure at the laryngospasm notch between the condyle of the mandible and the mastoid process can be effective in treating laryngospasm by causing an intense painful stimulus; this may function to terminate laryngospasm by arousing a semiconscious patient or by activating autonomic pathways. ${ }^{14}$

\section{Postobstructive Pulmonary Edema}

Postobstructive pulmonary edema, also known as negative-pressure pulmonary edema, may develop in spontaneously breathing patients when laryngospasm or other causes of airway obstruction occur following extubation. As a result of a forceful inspiratory effort in the setting of acute airway obstruction, significant negative intrapleural pressure is generated, leading to engorgement of the pulmonary vasculature and increased pulmonary capillary hydrostatic pressure that result in acute development of pulmonary edema. This condition is seen within minutes after extubation and usually presents with a decrease in $\mathrm{S}_{\mathrm{pO}_{2}}$ and pink frothy sputum. The incidence of this condition has been estimated to be $\sim 1$ in 1000 in the postoperative period, with young healthy males at increased risk. ${ }^{16}$ Other etiologies include epiglottitis, croup, foreign airway body, ETT obstruction, laryngeal tumor, and bilateral vocal cord paralysis. ${ }^{16}$ Management involves removing the obstruction, oxygen supplementation, and close monitoring. CPAP may help to expedite resolution of the edema.
In severe cases, re-intubation and mechanical ventilation may be necessary. ${ }^{16}$

\section{Vocal Cord Dysfunction}

Injury to the vagus nerve or the recurrent laryngeal nerve (the branch of the vagus nerve that provides motor innervation to the larynx) can cause vocal cord paralysis. This rare complication most often presents in thyroid, thoracic, or neck surgeries. Vocal cord dysfunction can also be caused by cuff pressure from the ETT near the anterior division of the recurrent laryngeal nerve. ${ }^{17}$ Unilateral vocal cord paralysis usually presents with uncomplicated hoarseness, which recovers within weeks. In contrast, bilateral vocal cord paralysis can cause airway obstruction, requiring immediate re-intubation. Recovery is often delayed, and a tracheostomy may be required. Diagnosis can be confirmed by fiberoptic evaluation.

Paradoxical vocal cord motion is a commonly misdiagnosed cause of postoperative stridor. It involves adduction of the vocal cords during inspiration, leading to inspiratory stridor and, in severe cases, near-total airway obstruction. The exact etiology is unknown, but many cases have been suspected to have a nonorganic psychogenic cause, and many of the described cases have been in patients with psychiatric illness. The diagnosis is made by observing vocal cord adduction during inspiration with indirect or flexible fiberoptic laryngoscopy. Treatment involves ensuring adequate oxygenation and ventilation and administration of mild sedation with benzodiazepines or opioids once the diagnosis is confirmed. More invasive treatment with re-intubation or tracheostomy can be avoided if correctly diagnosed. ${ }^{18}$

\section{Laryngeal Edema}

Laryngeal edema is an important cause of postextubation obstruction. This condition has various causes and can be classified as being supraglottic, retro-arytenoid, or subglottic. ${ }^{19}$ Supraglottic edema most often occurs as a result of surgical manipulation, positioning, hematoma formation, aggressive fluid management, decreased venous drainage, prolonged intubation, or coexisting conditions (eg, pre-eclampsia or angioedema). Subglottic edema is more often seen in children, particularly infants and neonates. Factors associated with the development of subglottic edema in children include tracheal intubation, intubation for $>1 \mathrm{~h}$, bucking on the ETT, change in head position, and a tight-fitting ETT. The etiology of retro-arytenoid edema is less well described, but may be due to local trauma or irritation. Usually, laryngeal edema presents as inspiratory stridor within 30-60 min of extubation, although it may occur as late as $6 \mathrm{~h}$ following extubation. Whatever the cause, management depends on the severity 
of the condition and includes humidified oxygen, nebulized racemic epinephrine, and placing the patient in a head-up position. When severe, laryngeal edema can lead to extubation failure and require re-intubation. ${ }^{19}$ Prophylactic steroids have been shown to be effective in preventing laryngeal edema in patients at high risk for developing the complication when administered at least $4 \mathrm{~h}$ before extubation. ${ }^{20}$

\section{Residual Neuromuscular Blockade}

Neuromuscular blocking drugs are frequently used during general anesthesia to facilitate intubation and optimize surgical conditions and are occasionally used in the ICU setting. Residual neuromuscular blockade (also referred to as postoperative residual curarization [PORC]), defined as a train-of-four ratio of $<0.9$, can manifest as weaning or extubation failure. Studies in postsurgical subjects have shown a high incidence of PORC at time of extubation whether or not reversal with neostigmine was administered. ${ }^{21}$ PORC has been shown to result in impaired pharyngeal function and upper airway obstruction, ${ }^{22,23}$ as well as reduction in peak expiratory flow and FVC. ${ }^{24}$ An increase in postoperative respiratory complications, including the need for re-intubation, has been seen in patients with PORC. 25

At a minimum, when neuromuscular blocking drugs are administered intra-operatively or in the ICU, the use of qualitative neuromuscular twitch monitoring should be utilized to assess the need for neuromuscular blockade reversal. Clinical tests (eg, ability to sustain a 5-s head lift or ability to sustain masseter muscle strength) and qualitative neuromuscular monitoring (eg, double-burst stimulation or sustained tetanic response) have been shown to have low sensitivity for detecting PORC. In patients at high risk for extubation failure, the use of quantitative neuromuscular twitch monitoring to ensure a train-of-four ratio of $>0.9$ may be indicated to maximize extubation success.

\section{Preventing Extubation Failure}

Evidence that extubation failure leads to increased rates of complications and death has led to efforts to identify methods of preventing the need for re-intubation. Although some studies have shown that noninvasive ventilation (NIV) can reduce re-intubation rates, ${ }^{26}$ most have shown no benefit in avoiding re-intubation when applied to all patients after extubation or when applied to patients with signs of postextubation respiratory failure. ${ }^{3,27}$ NIV may have a role in preventing extubation failure in certain subsets of patients, such as those with neuromuscular disease. ${ }^{28}$

The use of corticosteroids to reduce inflammatory airway edema and prevent extubation failure has been studied extensively. ${ }^{29}$ The DAS guidelines specify that ste- roids should be administered as soon as possible in patients at high risk for airway edema and continued for at least $12 \mathrm{~h}$. A single dose of steroids administered immediately before extubation is unlikely to be effective. ${ }^{6}$

\section{Weaning From Mechanical Ventilation}

Weaning from ventilatory support is an important prerequisite to extubation in critically ill patients. There is a fundamental difference between extubation after an elective intubation for a surgical procedure and extubation after intubation for acute respiratory failure. Weaning generally refers to the process of assessing for readiness of the patient to tolerate removal of mechanical ventilatory support, the performance of spontaneous breathing trials (SBTs) with minimum to no ventilatory support, and subsequent extubation when SBTs indicate that the patient will tolerate liberation from the ventilator. It is estimated that time spent in the weaning process makes up $40-50 \%$ of the entire duration of mechanical ventilation. ${ }^{30}$ There is evidence that weaning is frequently delayed, prolonging the duration of mechanical ventilation and increasing the risk of its associated complications. ${ }^{30}$

Weaning should be considered as early as possible to reduce the incidence of complications related to prolonged mechanical ventilation. ${ }^{30}$ This needs to be balanced, however, against the potential risk of initiating spontaneous breathing too early. ${ }^{1}$ Objective weaning parameters have only moderate predictive capability and do not facilitate weaning. ${ }^{31}$ For example, the use of the frequency/tidal volume ratio in the decision to initiate SBTs in one study resulted in a longer time to wean and similar outcomes, ${ }^{32}$ suggesting that there is no advantage to using this parameter to predict readiness. The current consensus is that objective weaning parameters should not be routinely used to determine readiness to wean. Instead, patients can be considered ready for weaning when there is evidence of clinical improvement of the original pathologic process that led to acute respiratory failure, cardiovascular stability with (at most) a minimum requirement for vasopressors, adequate mentation, efforts at spontaneous ventilation, and adequate oxygenation (defined as an arterial oxygen saturation of $>90 \%$ with $\mathrm{F}_{\mathrm{IO}_{2}} \leq 0.4$ and PEEP $\left.\leq 8 \mathrm{~cm} \mathrm{H}_{2} \mathrm{O}\right){ }^{1,30,33}$

Once readiness to wean has been determined, an SBT is performed as a diagnostic test to predict success of ventilator liberation. This involves a trial of spontaneous ventilation either with no assistance (through a T-piece) or with low-level mechanical support (CPAP or pressure support ventilation $\left.[\mathrm{PSV}] \leq 8 \mathrm{~cm} \mathrm{H}_{2} \mathrm{O}\right) \cdot{ }^{1}$ Multiple studies have failed to show superiority of one modality over another for SBTs. The rationale for the use of PSV has been to overcome the resistance of the ETT; however, the upper airway typically has a higher than normal resistance after prolonged intubation, so this compensation is typically 
Table 4. Causes of Weaning Failure

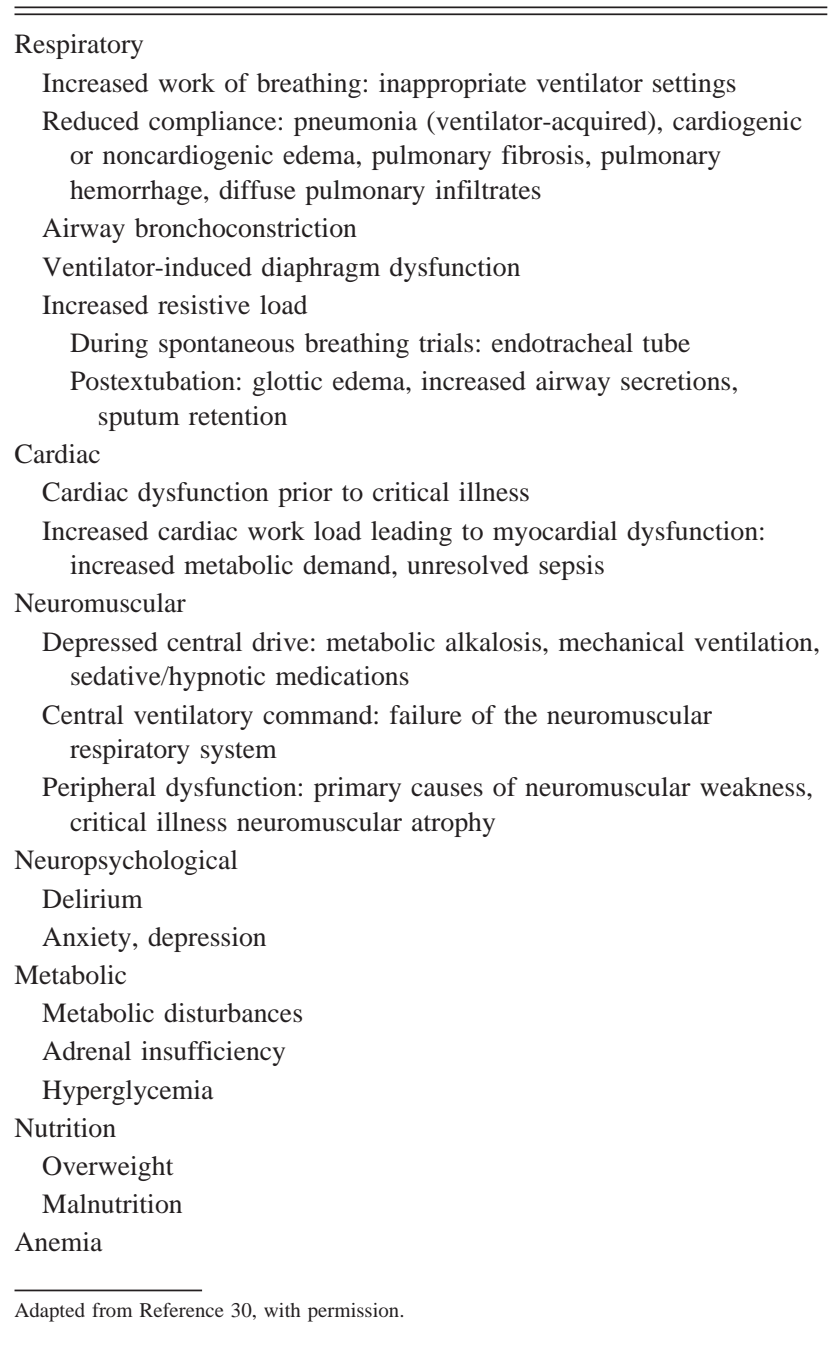

unnecessary. ${ }^{30,34}$ Automatic tube compensation, a ventilator setting that makes up for the pressure drop across the ETT, is comparable to low-level PSV or a T-piece. ${ }^{35}$ The duration of an SBT should be at least $30 \mathrm{~min}^{30}$; no benefit is gained from prolonging the duration of an SBT to 120 min. ${ }^{36,37}$

The rate of weaning failure after an initial SBT has been reported to be $25-40 \% .{ }^{30}$ Multiple etiologies for weaning failure have been identified (Table 4). Some subgroups of patients (such as those with COPD and hypercapnic respiratory failure) are at higher risk for weaning failure. ${ }^{38}$ For patients who fail an initial SBT, reversible causes of failure should be considered. ${ }^{30}$

A relatively common cause of SBT failure is cardiac dysfunction. During SBTs, the reduction in intrathoracic pressure leads to increased venous return and an increased left ventricular afterload, which can precipitate left ventricular failure and pulmonary edema. ${ }^{39,40}$ Echocardiography and serum brain natriuretic peptide levels have been used to assess cardiac dysfunction as a cause of weaning failure. ${ }^{41,42}$ Strategies for treatment include afterload reduction with vasodilators, preload reduction with diuretics, and CPAP.

NIV has been studied as a weaning method with the potential to decrease the length of invasive mechanical ventilation. Several studies have demonstrated that, in a subset of subjects with COPD exacerbation, NIV has a role in facilitating weaning, shortening the duration of intubation, decreasing the incidence of VAP, and reducing mortality in patients who have failed an SBT. ${ }^{27,30,43}$ In this setting, NIV can be instituted once a patient meets criteria for initiating an SBT, has a patent airway, and can clear secretions. ${ }^{2,44}$ NIV should not be used as a weaning method in patients who would be technically difficult to re-intubate. ${ }^{44}$ Evidence does not support a role for NIV in nonCOPD patients who fail an SBT. ${ }^{44}$

\section{Decision to Extubate}

A limitation of SBTs is that they do not assess airway patency, ${ }^{45}$ which must be taken into consideration when determining which patients are at risk for extubation failure. Two maneuvers are often performed when determining the feasibility of extubation. The first is visualization of the laryngeal inlet before extubation, which can be performed by direct laryngoscopy, indirect/video laryngoscopy, or flexible fiberoptic laryngoscopy. This practice is frequently taught as a method to evaluate the airway before extubation for edema and to assess the feasibility of re-intubation. Nonetheless, the authors believe this practice is of limited value. The ETT blocks the laryngoscopist's view of the laryngeal inlet, and the airway anatomy is deformed by the ETT in situ, leading to an underestimation of the difficulty of re-intubation. No studies have shown that laryngoscopy before extubation decreases the incidence of re-intubation.

The second maneuver commonly performed is the cuffleak test. A qualitative cuff-leak test is accomplished by removing a spontaneously ventilating patient from the ventilation circuit, deflating the ETT cuff, and occluding the end of the ETT with a finger. ${ }^{46,47}$ If no significant laryngeal edema is present, the patient will be able to breathe around the ETT, as evidenced by auscultation of breath sounds or by the measurement of exhaled carbon dioxide from the oral cavity. ${ }^{48}$ A quantitative cuff-leak test is accomplished by comparing the exhaled tidal volumes with the cuff inflated and deflated while the patient is on volume control mechanical ventilation. A difference between the inflated and deflated tidal volumes of at least $10-25 \%$ or $110-130 \mathrm{~mL}$ in an adult suggests a low probability of laryngeal edema. ${ }^{49,50}$ Higher cutoff values may be useful in patients with a difficult airway for whom re-intubation difficulty is expected. ${ }^{7}$ A meta-analysis of the cuff-leak 
Table 5. Routine Extubation Criteria

Breathing frequency $<30$ breaths $/$ min

Maximum inspiratory pressure $<-20 \mathrm{~cm} \mathrm{H}_{2} \mathrm{O}$

Vital capacity $>15 \mathrm{~mL} / \mathrm{kg}$

Tidal volume $>6 \mathrm{~mL} / \mathrm{kg}$

Hemodynamically stable with no significant inotropic support

Adequate gas exchange (baseline $\mathrm{O}_{2}$ saturation $\geq 93 \%$; no significant acidosis by arterial blood gas, if applicable)

Adequate neuromuscular block reversal (5-s sustained head lift)

From Reference 52, with permission.

test has shown moderate accuracy of the test for predicting postextubation stridor and low accuracy for predicting the need for re-intubation. ${ }^{51}$ In the difficult airway, however, where the pretest probability of extubation failure is greater, the cuff-leak test may still provide valuable clinical information to assist in the decision of whether to proceed with extubation.

In the authors' opinion, a cuff-leak test should be performed on any patient who is considered to be at risk for extubation failure. Although the presence of a cuff leak does not necessarily guarantee successful extubation, the strategic extubation of a difficult airway in the presence of a cuff leak is reasonable. In the absence of a cuff leak, controlled extubation over an airway exchange catheter (AEC) may be considered; however, it may be prudent to delay extubation if re-intubation is expected to be particularly difficult, especially if conditions may improve in time. This must be balanced against the risks of prolonged mechanical ventilation. Extubation might also be delayed when the lack of a cuff leak is thought to be due to airway inflammation as a result of traumatic intubation or upper airway, maxillofacial, or neck surgery. In these situations, there is some evidence for the administration of corticosteroids at least $4 \mathrm{~h}$ before extubation.

\section{Extubation After Elective Intubation}

The decision to extubate after an elective intubation for general anesthesia depends on several additional factors, including the patient's preoperative status, the intra-operative course, and the expected postoperative recovery. Among the factors that must be considered are the patient's intra-operative course (including the procedure length, type, and location), the patient's underlying medical conditions (such as lung or heart disease), and the patient's current clinical status (eg, fluid balance, hemodynamic stability, level of consciousness, muscle strength, and temperature). Ventilatory status should be assessed, and standard criteria for extubation should be met (Table 5 ). If the patient has had a labile intra-operative course or problems in any of the above areas, the patient should not be extubated in the operating room immediately at the end of surgery, but should be taken to the post-anesthesia care unit or ICU for further stabilization before extubation.

\section{Extubation of the Difficult Airway}

When formulating an extubation plan, it is important to stratify not only the risk of extubation failure, but also the feasibility of re-intubation. Therefore, extubation of the difficult airway requires special consideration. A difficult airway, as defined in the ASA "Practice Guidelines for Management of the Difficult Airway," is "the clinical situation in which a conventionally trained anesthesiologist experiences difficulty with face mask ventilation of the upper airway, difficulty with tracheal intubation, or both." 53 Deciding to extubate a patient with a known or suspected difficult airway can be problematic. The main goal of extubating the difficult airway, as any airway, is to avoid re-intubation, if at all possible. This goal is extremely important when faced with a difficult airway because reintubation is almost always more hazardous. Many conditions associated with difficult mask ventilation and/or intubation may also predispose to a higher risk for failed extubation. Re-intubation then poses a greater challenge in the difficult airway. Because of the potential for serious morbidity related to failed extubation if re-intubation is not quickly achieved, clinicians need to be armed with techniques that successfully address the specific challenges in extubation of the difficult airway and appreciate the potential complications associated with extubation.

Clearly, if difficulty with mask ventilation or endotracheal intubation is encountered at induction, particular caution should be exercised at the time of extubation due to the expected difficulty of re-intubation, if needed. Often, there is a higher rate of failed extubation in this scenario due to airway trauma as a result of multiple attempts to initially secure the airway. Airway edema and swelling from the multiple attempts can lead to obstruction after extubation and an inability to adequately ventilate.

On the other hand, there may be no difficulty with the initial airway management, but because of changes to the airway that occur due to either surgery or prolonged intubation, difficulty may be encountered at extubation. It is important to remember that simply because an airway is initially easy to manage does not mean that airway management will be easy after completion of surgery. Thyroidectomy, carotid endarterectomy, anterior cervical spine procedures, and maxillofacial surgery are only a few examples of surgical procedures around the airway that can lead to a difficult airway at extubation. Prolonged intubation can result in laryngeal and pharyngeal edema, macroglossia, and laryngeal and tracheobronchial injury, which may increase the risk for extubation failure and lead to difficulty with re-intubation, if necessary. Many extuba- 


\section{Tracheal Extubation}

tion problems associated with surgical procedures involve postoperative bleeding, nerve damage, or direct tissue trauma. Caution should be observed with devices placed near the airway intra- and postoperatively (eg, cervical collars, maxillomandibular fixation, or large dressings on the head or neck). These devices may restrict airway access and lead to difficulty with re-intubation.

When deciding whether to extubate the patient with a difficult airway, communication with the surgical and/or critical care team is essential. It is important that all parties involved in the patient's care be made aware of the nature of the potential airway difficulty, and a clear discussion of the risks and benefits of extubation versus prolonged intubation should be performed physician-to-physician. Consideration of the patient's future operative schedule should also be taken into account; it makes no sense to extubate a patient with a difficult airway who will be returning the next morning for follow-up surgery.

\section{Extubation Strategies}

Once the decision has been made to extubate, strategies for a safe extubation can be formulated. The clinician must understand the various options for extubation and formulate a plan of action to regain control of the airway if extubation fails. Extubation following an elective intubation for general anesthesia has different considerations compared with extubation following intubation for acute respiratory failure.

The ASA Task Force on Management of the Difficult Airway recommends consideration of the risks and benefits of an awake extubation versus extubation in a deeply anesthetized state..$^{53}$ The so-called deep extubation has been described in patients with both easy and difficult airways. Extubation of a patient while in a deep plane of anesthesia has been widely taught as a means to decrease the risk of laryngospasm or bronchospasm, but there are no adequate studies indicating any real benefit from this approach. Although a deep extubation may decrease the risk of coughing and bucking before extubation, the risk of airway obstruction due to the effects of deep anesthesia on pharyngeal muscle tone is significant; therefore, we feel that this practice should generally be discouraged in the face of a difficult airway. Awake extubation is the most appropriate method of removing the ETT in most patients with a difficult airway. Likewise, in the patient intubated for acute respiratory failure, recovery from sedation is recommended before extubation due to the nature of the need for mechanical ventilation in this patient population.

In patients considered to be at low risk for extubation failure, a standard extubation can be performed. This involves preoxygenation with an $\mathrm{F}_{\mathrm{IO}_{2}}$ of 1.0 , suctioning of the trachea and oropharynx, and extubation under close

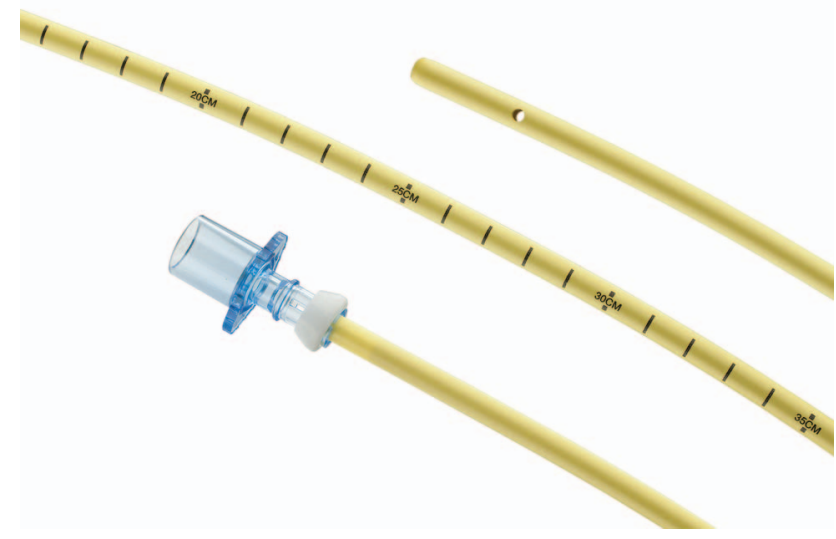

Fig. 1. Airway exchange catheter. Courtesy Cook Medical.

supervision until airway patency and ability to tolerate extubation are confirmed.

For the patient at risk for extubation failure, particularly the patient with a difficult airway, one of several alternative strategies can be utilized, as summarized in the DAS guidelines. ${ }^{6}$ These include AEC-assisted extubation, laryngeal mask airway-assisted extubation, and the use of remifentanil (an intravenous ultrashort-acting opioid). ${ }^{6}$

\section{Airway Exchange Catheter-Assisted Extubation}

The ASA practice guidelines and the DAS guidelines discuss the use of a stylet-type device or bougie to aid in re-intubation if extubation fails. ${ }^{6,53}$ The stylet is inserted through the ETT, and the ETT is removed over the stylet. The stylet is left in the airway until the risk of extubation failure is no longer significant; if re-intubation becomes necessary, the stylet is used as a guide over which an ETT is advanced. Many devices have been used in the extubation of the difficult airway, including bronchoscopes, nasogastric tubes, gum elastic bougies, and suction tubes. ${ }^{6}$ Most of these devices were first described for ETT exchange, and many are still used for that purpose.

AECs are long hollow semirigid catheters that are designed for ETT exchange, but they make suitable catheters for extubation of the difficult airway. There are numerous manufacturers of these types of catheters, but all are based on the same principle: a long hollow tube or stylet is inserted into the in situ ETT to a predetermined depth, the ETT is removed over the catheter, and the catheter remains in place to act as a guide for intubation if re-intubation is necessary, to insufflate oxygen via jet ventilation, or to intermittently measure end-tidal carbon dioxide from the trachea. These products come in a variety of sizes and have different features depending on the manufacturer. A 


\section{Tracheal Extubation}

frequently used AEC is the Cook AEC (Cook Medical, Bloomington, Indiana) (Fig. 1).

The recommended size of the Cook AEC for use in most adult patients is 11 French. This size of AEC is well tolerated by an awake patient and allows for re-intubation with ETTs as small as $4.5 \mathrm{~mm}$ in inner diameter. Larger patients can usually accommodate a 14 French AEC, which will allow for re-intubation with an ETT with an inner diameter of at least $5.5 \mathrm{~mm}$. If it is known that ETT exchange is required (eg, secondary to a ruptured cuff, resulting in a cuff leak), it may be prudent to use the larger diameter AEC. Smaller AECs can easily be used for the purpose of possible re-intubation and are usually tolerated without airway topicalization; if necessary, 2-4\% lidocaine can be instilled through the AEC to increase tolerance of the AEC. This maneuver should be performed while the patient is still anesthetized to minimize coughing. Once placed, AECs should be taped in place to prevent migration or accidental extubation. The AEC should be well labeled, as it can be easily mistaken for a feeding tube due to its similar diameter and color (light yellow).

Carinal irritation is a common reason for intolerance due to discomfort, bronchospasm, and paroxysmal coughing; therefore, proper depth assessment at the time of extubation is essential. Periodic discussion with the patient regarding airway concerns is also important, as patient understanding of the clinical implications of a lost airway can increase their tolerance threshold.

Cook AECs come with two Rapi-Fit adapters: one with a 15-mm connector for connection to the anesthesia circuit or Ambu bag and one with a Luer-Lok connector for jet ventilation. Before use of an AEC for oxygenation, ventilation, or re-intubation, it is imperative to confirm proper placement by visualization (with direct or indirect laryngoscopy) or by capnography. The catheters have distance markings to allow proper depth determination. To avoid barotrauma or bronchial perforation from postcarinal placement, these catheters should be inserted to a depth of $20-22 \mathrm{~cm}$ (no more than $25 \mathrm{~cm}$ ) when used for orotracheal intubation; when used for nasotracheal intubation, a depth of $27-30 \mathrm{~cm}$ is appropriate. Due to the risk of barotrauma, oxygen insufflation or jet ventilation should be utilized only as a life-saving measure and only in the presence of an unobstructed upper airway. ${ }^{6}$

When re-intubation over an AEC is attempted, simultaneous direct or video laryngoscopy is recommended to retract the soft tissue and facilitate advancement of the ETT over the AEC. The smallest effective size of ETT should be used to minimize impingement of the ETT on laryngeal structures. Alternatively, the Parker Flex-Tip ETT (Parker Medical, Englewood, Colorado) is designed with a soft, curved, anteriorly located bevel, minimizing the gap between the AEC and the lumen of the ETT and facilitating smooth passage into the trachea. ${ }^{52}$

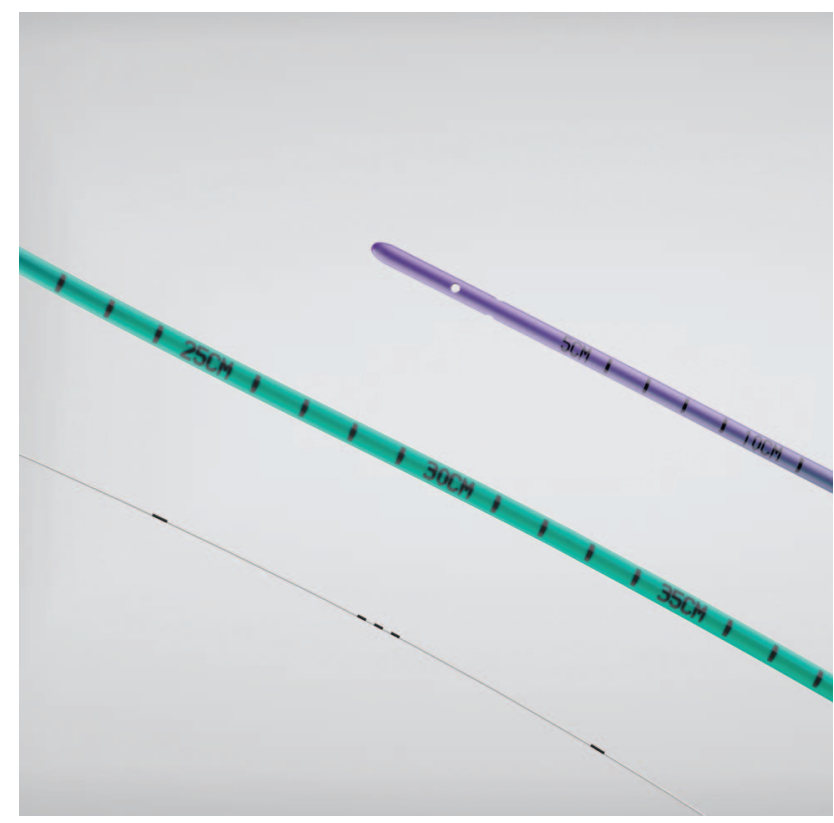

Fig. 2. Staged extubation set, which includes a 14 French staged re-intubation catheter and a 0.035 -inch staged extubation wire. Courtesy Cook Medical.

Cook Medical has recently developed a staged extubation set that is specifically designed for extubation of the difficult airway (Fig. 2). Currently available in Europe, Australia, and Canada, it consists of the staged re-intubation catheter, a 14 French AEC with a blunt soft tip, and a staged extubation wire (a 0.035 -inch flexible wire with a polymeric coating that provides minimum irritation and maximum patient comfort while in situ, but with enough stiffness to provide a reliable track for the re-intubation catheter). ${ }^{54}$ The staged extubation wire is advanced through the ETT before extubation to a predetermined depth. The ETT is removed while the wire remains secured in place until the risk of extubation failure has been determined to be acceptable. In the event that re-intubation becomes necessary, the staged re-intubation catheter is advanced over the wire, and an ETT is then advanced over the re-intubation catheter.

\section{Laryngeal Mask Airway-Assisted Extubation}

Extubation under general anesthesia prevents coughing and adverse hemodynamic effects at the time of extubation, which may be undesirable in patients with certain risk factors (eg, cardiac disease or a reactive airway) or after specific surgical procedures (eg, neurosurgical or maxillofacial procedures). However, this practice may result in airway obstruction and the need for airway support maneuvers and, as such, may not be appropriate for the at-risk extubation. The laryngeal mask airway has a role in facilitating extubation under general anesthesia in patients at 
high risk for failure by acting as a bridge to successful extubation. Hemodynamic stress and coughing or bucking have been shown to be reduced during emergence with a laryngeal mask airway in place compared to tracheal extubation in both the awake and deeply anesthetized states. ${ }^{55,56}$

Various methods for using the laryngeal mask airway at extubation have been described. ${ }^{6}$ Insertion of a laryngeal mask airway after extubation has been described with both the LMA Classic and the LMA ProSeal (LMA North America, San Diego, California). ${ }^{6,55}$ The use of fiberoptic bronchoscopy in combination with a laryngeal mask airway is useful in settings in which evaluation of vocal cord function is an important part of the extubation plan, such as in complex thyroid surgery. ${ }^{57} \mathrm{~A}$ common technique of ETT/ laryngeal mask airway exchange involves first placing the laryngeal mask airway behind the ETT, a procedure often termed the Bailey maneuver after Dr PM Bailey. ${ }^{58}$

\section{Remifentanil Extubation Technique}

The use of remifentanil is another technique in the DAS guidelines to facilitate a difficult extubation. ${ }^{6}$ A remifentanil infusion at the time of extubation has been shown to reduce coughing and hemodynamic changes associated with tracheal extubation..$^{59}$ Due to the very short half-life of remifentanil, infusions can be easily titrated to an optimal clinical effect, minimizing the risk of coughing (from too low a dose) and apnea (from too high a dose). ${ }^{6}$ This strategy should be considered for patients in whom the adverse hemodynamic effects and coughing associated with extubation are undesired, such as patients with significant cardiac or reactive airway disease, or after certain surgical procedures. ${ }^{6}$

\section{Treatment of Extubation Failure}

The onset of respiratory distress following extubation should alert the clinician that the patient is failing extubation. Hypercapnia, hypoxia, and abdominal breathing are all signs that re-intubation may be necessary. Severe postextubation stridor and an inability to manage secretions are additional indications for re-intubation.

Patients who fail extubation have an increased mortality rate compared with patients who are successfully extubated on the first attempt or patients who fail their first breathing trial but are not extubated. ${ }^{3,60}$ This suggests that extubation failure itself independently increases mortality. Studies have also shown that among patients who require re-intubation, mortality is higher in patients in whom reintubation is delayed. NIV has not been shown to reduce the rates of re-intubation, and it can increase mortality by delaying re-intubation. ${ }^{61}$ Therefore, the evidence suggests that timely re-intubation in the event of failure is of utmost importance. Clinicians should be prepared to promptly assess the patient's response to extubation and act immediately when it is evident that respiratory failure is imminent. ${ }^{8}$

\section{Unplanned Extubation}

Unplanned extubation is a common event in the ICU in patients on mechanical ventilation, who frequently require the need for re-intubation. Unplanned extubation can be due to the actions of the patient (deliberate) or during routine nursing and medical care (unintentional). ${ }^{62}$ Risk factors for unplanned extubation include low levels of sedation, trips out of the ICU, male gender, obtaining a portable chest radiograph, and 1:3 nurse-to-patient ratios. ${ }^{62-64}$ The use of restraints has not shown to decrease the incidence of unplanned extubation and, in some studies, was associated with higher rates of re-intubation. ${ }^{63,65}$

Patients who experience an unplanned extubation before weaning criteria are met should be immediately reintubated. ${ }^{66}$ NIV may have a benefit in managing unplanned extubation in patients who have met weaning criteria and who are able to manage their secretions. ${ }^{66}$

\section{Future Research}

Future research on extubation should be focused on individual predictors of extubation failure and development of techniques to maximize the rate of successful extubation in patients at high risk for extubation failure. The various methods of performing the cuff-leak test should be studied to identify an approach that provides the highest predictive power. In addition, the specific subsets of patients in whom the test is of the highest value need to be elucidated.

Pathophysiologic conditions that contribute to weaning failure also need to be identified, along with strategies to facilitate weaning in these patients. ${ }^{30} \mathrm{~A}$ specific example is the need for reliable methods of assessing weaning failure due to cardiac dysfunction and identification of therapies to improve weaning success in this scenario. The role of NIV in the process of weaning from ventilatory support and in prevention of the need for re-intubation must also be further studied. Current evidence for the role of NIV in weaning and extubation is equivocal, with some studies showing a potential benefit with NIV, ${ }^{26}$ but many trials showing no advantage when used in unselected populations. ${ }^{3,27}$ Further research may possibly identify patient subgroups in whom the technique may be of benefit, such has been shown for patients with COPD exacerbation and neuromuscular disease. ${ }^{27,28}$ 


\section{Tracheal Extubation}

\section{Conclusions}

Due to the complications associated with prolonged intubation, patients receiving invasive mechanical ventilation should be extubated as expeditiously as possible. However, the risks associated with extubation failure and reintubation demand that the process of extubation be managed by practitioners with a detailed understanding of the causes of extubation failure and the potential complications. A pre-established extubation plan with considerations made for the possible need for re-intubation is of the utmost importance.

\section{REFERENCES}

1. Epstein SK. Weaning from ventilatory support. Curr Opin Crit Care 2009;15(1):36-43

2. Hess DR. The role of noninvasive ventilation in the ventilator discontinuation process. Respir Care 2012;57(10):1619-1625.

3. Epstein SK, Ciubotaru RL, Wong JB. Effect of failed extubation on the outcome of mechanical ventilation. Chest 1997;112(1):186-192.

4. Peterson GN, Domino KB, Caplan RA, Posner KL, Lee LA, Cheney FW. Management of the difficult airway: a closed claims analysis. Anesthesiology 2005;103(1):33-39.

5. Cook TM, Woodall N, Frerk C. Major complications of airway management in the UK: results of the Fourth National Audit Project of the Royal College of Anaesthetists and the Difficult Airway Society. Part 1: anaesthesia. Brit J Anaesth 2011;106(5):617-631.

6. Difficult Airway Society Extubation Guidelines Group, Popat M, Mitchell V, Dravid R, Patel A, Swampillai C, Higgs A. Difficult Airway Society Guidelines for the management of tracheal extubation. Anaesthesia 2012;67(3):318-340.

7. Cavallone LF, Vannucci A. Review article: extubation of the difficult airway and extubation failure. Anesth Analg 2013;116(2):368383.

8. Epstein SK. Decision to extubate. Intensive Care Med 2002;28(5): 535-546.

9. Rothaar RC, Epstein SK. Extubation failure: magnitude of the problem, impact on outcomes, and prevention. Curr Opin Crit Care 2003; 9(1):59-66.

10. Thille AW, Harrois A, Schortgen F, Brun-Buisson C, Brochard L. Outcomes of extubation failure in medical intensive care unit patients. Crit Care Med 2011;39(12):2612-2618

11. Sellares J, Ferrer M, Cano E, Loureiro H, Valencia M, Torres A. Predictors of prolonged weaning and survival during ventilator weaning in a respiratory ICU. Intensive Care Med 2011;37(5):775-784.

12. Krinsley JS, Reddy PK, Iqbal A. What is the optimal rate of failed extubation? Crit Care 2012;16(1):111.

13. Namen AM, Ely EW, Tatter SB, Case LD, Lucia MA, Smith A, et al. Predictors of successful extubation in neurosurgical patients. Am J Respir Crit Care Med 2001;163(3 Pt 1):658-664.

14. Al-alami AA, Zestos MM, Baraka AS. Pediatric laryngospasm: prevention and treatment. Curr Opin Anaesthesiol 2009;22(3):388-395.

15. Silva DA, Sanders I. Continuous positive airway pressure as a promoter of laryngospasm during halothane anesthesia. Ann Otol Rhinol Laryngol 1992;101(11):893-896.

16. Udeshi A, Cantie SM, Pierre E. Postobstructive pulmonary edema. J Crit Care 2010;25(3):538.e1-e5.

17. Ellis PD, Pallister WK. Recurrent laryngeal nerve palsy and endotracheal intubation. J Laryngol Otol 1975;89(8):823-826.
18. Larsen B, Caruso LJ, Villariet DB. Paradoxical vocal cord motion: an often misdiagnosed cause of postoperative stridor. J Clin Anesth 2004;16(3):230-234.

19. Hartley M, Vaughan RS. Problems associated with tracheal extubation. Br J Anaesth 1993;71(4):561-568.

20. Jaber S, Jung B, Chanques G, Bonnet F, Marret E. Effects of steroids on reintubation and post-extubation stridor in adults: meta-analysis of randomised controlled trials. Crit Care 2009;13(2):R49.

21. Murphy GS. Residual neuromuscular blockade: incidence, assessment, and relevance in the postoperative period. Minerva Anestesiol 2006;72(3):97-109.

22. Sundman E, Witt H, Olsson R, Ekberg O, Kuylenstierna R, Eriksson LI. The incidence and mechanisms of pharyngeal and upper esophageal dysfunction in partially paralyzed humans: pharyngeal videoradiography and simultaneous manometry after atracurium. Anesthesiology 2000;92(4):977-984.

23. Eikermann M, Vogt FM, Herbstreit F, Vahid-Dastgerdi M, Zenge MO, Ochterbeck C, et al. The predisposition to inspiratory upper airway collapse during partial neuromuscular blockade. Am J Respir Crit Care Med 2007;175(1):9-15.

24. Kumar GV, Nair AP, Murthy HS, Jalaja KR, Ramachandra K, Parameshwara G. Residual neuromuscular blockade affects postoperative pulmonary function. Anesthesiology 2012;117(6):1234-1244.

25. Murphy GS, Szokol JW, Marymont JH, Greenberg SB, Avram MJ, Vender JS. Residual neuromuscular blockade and critical respiratory events in the postanesthesia care unit. Anesth Analg 2008;107(1): 130-137.

26. Ornico SR, Lobo SM, Sanches HS, Deberaldini M, Tófoli LT, Vidal AM, et al. Noninvasive ventilation immediately after extubation improves weaning outcome after acute respiratory failure: a randomized controlled trial. Crit Care 2013;17(2):R39.

27. Zhu F, Liu ZL, Long X, Wu XD, Zhou J, Bai CX, Li SQ. Effect of noninvasive positive pressure ventilation on weaning success in patients receiving invasive mechanical ventilation: a meta-analysis. Chin Med J 2013;126(7):1337-1343.

28. Vianello A, Arcaro G, Braccioni F, Gallan F, Marchi MR, Chizio S, et al. Prevention of extubation failure in high-risk patients with neuromuscular disease. J Crit Care 2011;26(5):517-524.

29. McCaffrey J, Farrell C, Whiting P, Dan A, Bagshaw SM, Delaney AP. Corticosteroids to prevent extubation failure: a systematic review and meta-analysis. Intensive Care Med 2009;35(6):977-86.

30. Boles JM, Bion J, Connors A, Herridge M, Marsh B, Melot C, et al. Weaning from mechanical ventilation. Eur Respir J 2007;29(5):10331056.

31. Meade M, Guyatt G, Cook D, Griffith L, Sinuff T, Kergl C, et al. Predicting success in weaning from mechanical ventilation. Chest 2001;120(6 Suppl):400S-424S.

32. Tanios MA, Nevins ML, Hendra KP, Cardinal P, Allan JE, Naumova EN, Epstein SK. A randomized, controlled trial of the role of weaning predictors in clinical decision making. Crit Care Med 2006; 34(10):2530-2535.

33. Thille AW, Cortés-Puch I, Esteban A. Weaning from the ventilator and extubation in ICU. Curr Opin Crit Care 2013;19(1):57-64.

34. Mehta S, Nelson DL, Klinger JR, Buczko GB, Levy MM. Prediction of post-extubation work of breathing. Crit Care Med 2000;28(5): 1341-1346.

35. Haberthür C, Mols G, Elsasser S, Bingisser R, Stocker R, Guttmann J. Extubation after breathing trials with automatic tube compensation, T-tube, or pressure support ventilation. Acta Anaesthesiol Scand 2002;46(8):973-979.

36. Perren A, Domenighetti G, Mauri S, Genini F, Vizzardi N. Protocoldirected weaning from mechanical ventilation: clinical outcome in patients randomized for a 30 -min or 120-min trial with pressure support ventilation. Intensive Care Med 2002;28(8):1058-1063. 


\section{Tracheal Extubation}

37. Esteban A, Alía I, Tobin MJ, Gil A, Gordo F, Vallverdú I, et al. Effect of spontaneous breathing trial duration on outcome of attempts to discontinue mechanical ventilation. Spanish Lung Failure Collaborative Group. Am J Respir Crit Care Med 1999;159(2):512518.

38. Brochard L, Rauss A, Benito S, Conti G, Mancebo J, Rekik N, et al. Comparison of three methods of gradual withdrawal from ventilatory support during weaning from mechanical ventilation. Am J Respir Crit Care Med 1994;150(4):896-903.

39. Lemaire F, Teboul JL, Cinotti L, Giotto G, Abrouk F, Steg G, et al. Acute left ventricular dysfunction during unsuccessful weaning from mechanical ventilation. Anesthesiology 1988;69(2):171-179.

40. Buda AJ, Pinsky MR, Ingels NB Jr, Daughters GT 2nd, Stinson EB, Alderman EL. Effect of intrathoracic pressure on left ventricular performance. N Engl J Med 1979;301(9):453-459.

41. Mekontso Dessap A, Roche-Campo F, Kouatchet A, Tomicic V, Beduneau G, Sonneville R, et al. Natriuretic peptide-driven fluid management during ventilator weaning: a randomized controlled trial. Am J Respir Crit Care Med 2012;186(12):1256-1263.

42. Moschietto S, Doyen D, Grech L, Dellamonica J, Hyvernat H, Bernardin G. Transthoracic echocardiography with Doppler tissue imaging predicts weaning failure from mechanical ventilation: evolution of the left ventricle relaxation rate during a spontaneous breathing trial is the key factor in weaning outcome. Crit Care 2012;16(3):R81.

43. Epstein SK. Noninvasive ventilation to shorten the duration of mechanical ventilation. Respir Care 2009;54(2):198-208; discussion 208111.

44. Epstein SK, Durbin CG Jr. Should a patient be extubated and placed on noninvasive ventilation after failing a spontaneous breathing trial? Respir Care 2010;55(2):198-206; discussion 207-198.

45. Savi A, Teixeira C, Silva JM, Borges LG, Pereira PA, Pinto KB, et al. Weaning predictors do not predict extubation failure in simpleto-wean patients. J Crit Care 2012;27(2):221.e1-221.e8.

46. Fisher MM, Raper RF. The 'cuff-leak' test for extubation. Anaesthesia 1992;47(1):10-12.

47. Maury E, Guglielminotti J, Alzieu M, Qureshi T, Guidet B, Offenstadt G. How to identify patients with no risk for postextubation stridor? J Crit Care 2004;19(1):23-28.

48. Eng MR, Wu TT, Brock-Utne JG. An adjuvant of the cuff leak test. Anaesthesia 2009;64(4):452.

49. De Bast Y, De Backer D, Moraine JJ, Lemaire M, Vandenborght C, Vincent JL. The cuff leak test to predict failure of tracheal extubation for laryngeal edema. Intensive Care Med 2002;28(9):1267-1272.

50. Engoren M. Evaluation of the cuff-leak test in a cardiac surgery population. Chest 1999;116(4):1029-1031

51. Ochoa ME, Marín Mdel C, Frutos-Vivar F, Gordo F, Latour-Pérez J, Calvo E, Esteban A. Cuff-leak test for the diagnosis of upper airway obstruction in adults: a systematic review and meta-analysis. Intensive Care Med 2009;35(7):1171-1179.
52. Ferrario L. Extubation catheters. In: Hagberg CA, Artime CA, Daily WH, editors. The difficult airway: a practical guide. Oxford: Oxford University Press; 2013:136.

53. Apfelbaum JL, Hagberg CA, Caplan RA, Blitt CD, Connis RT, Nickinovich DG, et al. Practice guidelines for management of the difficult airway: an updated report by the American Society of Anesthesiologists Task Force on Management of the Difficult Airway. Anesthesiology 2013;118(2):251-270.

54. Cook staged extubation set (package insert). Bloomington, IN: Cook Medical; 2013.

55. Russo SG, Goetze B, Troche S, Barwing J, Quintel M, Timmermann A. LMA-ProSeal for elective postoperative care on the intensive care unit: a prospective, randomized trial. Anesthesiology 2009;111(1): 116-121.

56. Bennett SR, Grace D, Griffin SC. Cardiovascular changes with the laryngeal mask airway in cardiac anaesthesia. Br J Anaesth 2004; 92(6):885-887

57. Ellard L, Brown DH, Wong DT. Extubation of a difficult airway after thyroidectomy: use of a flexible bronchoscope via the LMAClassic. Can J Anaesth 2012;59(1):53-57.

58. Nair I, Bailey PM. Use of the laryngeal mask for airway maintenance following tracheal extubation. Anaesthesia 1995;50(2):174-175.

59. Nho JS, Lee SY, Kang JM, Kim MC, Choi YK, Shin OY, et al. Effects of maintaining a remifentanil infusion on the recovery profiles during emergence from anaesthesia and tracheal extubation. Br J Anaesth 2009;103(6):817-821.

60. Epstein SK, Ciubotaru RL. Independent effects of etiology of failure and time to reintubation on outcome for patients failing extubation. Am J Respir Crit Care Med 1998;158(2):489-493.

61. Esteban A, Frutos-Vivar F, Ferguson ND, Arabi Y, Apezteguía C, González M, et al. Noninvasive positive-pressure ventilation for respiratory failure after extubation. N Engl J Med 2004;350(24):24522460

62. de Groot RI, Dekkers OM, Herold IH, de Jonge E, Arbous MS. Risk factors and outcomes after unplanned extubations on the ICU: a case-control study. Crit Care 2011;15(1):R19.

63. Curry K, Cobb S, Kutash M, Diggs C. Characteristics associated with unplanned extubations in a surgical intensive care unit. Am J Crit Care 2008;17(1):45-51

64. Tanios MA, Epstein SK, Livelo J, Teres D. Can we identify patients at high risk for unplanned extubation? A large-scale multidisciplinary survey. Respir Care 2010;55(5):561-568.

65. Chang LY, Wang KW, Chao YF. Influence of physical restraint on unplanned extubation of adult intensive care patients: a case-control study. Am J Crit Care 2008;17(5):408-415.

66. Eryüksel E, Karakurt S, Celikel T. Noninvasive positive pressure ventilation in unplanned extubation. Ann Thorac Med 2009;4(1):1720.

\section{Discussion}

Blank: I appreciate the excellent talk, Carin. I have a couple comments and one question. You mentioned residual neuromuscular blockade. Of course, the literature really supports this as a significant cause of respiratory morbidity, not only from upper airway obstruction, but also from further decreases in $\mathrm{FEV}_{1}$ and $\mathrm{FVC}$ in patients who have risk factors for that. Weaning failure can also be attributed to cardiac causes. Transition to negative-pressure ventilation is, of course, associated with pretty significant changes in cardiac and respiratory interactions. The transition to spontaneous ventilation can significantly alter both ventricular preload and afterload, especially LV [left ventricular] afterload. I know there's literature out there regarding weaning patients with OSA [obstructive sleep apnea] and LV dysfunction. I wondered if you had come across anything in your searches of the literature on those kinds of considerations.

Hagberg: They really haven't specifically addressed that subset of patients, but now that you mention it, there's so much work to be done in 
this area. I know you specialize in cardiac, right? So this might be a great study for you to do at your institution.

Blank: I've been trying to talk Stephen [Collins] into it.

Hagberg: We really do need more research. So often it's anecdotal or what practice has been. I would encourage you and your younger colleague to think about coming up with a protocol for these more problematic patients. You know, as I said, the ASA [American Society of Anesthesiologists] guidelines ${ }^{1}$ are really just guidelines; it's not an algorithmic approach or specifically related to these types of patients. I really think that now that the DAS [Difficult Airway Society] guidelines $^{2}$ have gone to an algorithmic approach, the ASA will be looking at that, too, which I encourage.

Hess: I think there's a lot of confusion around cuff-leak tests and how to do them. For example, in the ICU, I've never seen the cuff-leak test done as I know you do in the OR [operating room], where you let the cuff down and you put your thumb over the end of the tube. What we do in the ICU is apply positive pressure to the trachea, let the cuff down, and then try to qualitatively or quantitatively assess the amount of leak. I think it would be of great service to the critical care community if we had a standardized way of doing this, and not only a standardized way of doing it, but a true indication of when we should do it because the value of the cuff-leak test is lost if you do it on everybody: there are too many false positives and false negatives. In patients who are at risk, it may have a place.

Hagberg: You're absolutely right. There's not a good standardized method; it's not uniform. There is a need for that. So it's interesting that we're discussing areas where there is further work to be done, and it seems to be going toward more standardization. In all our practice, things are becoming more standardized; there's just less room for error. So you're absolutely right; this is a problem, and we need to get better at it.

Hess: I find it intriguing that, in your view from the OR, you would extubate someone to an LMA [laryngeal mask airway]. I've never seen that done. In the ICU, our approach would be to extubate somebody to NIV [noninvasive ventilation]. I find it intriguing that you have a patient who's morbidly obese and who, no question, needs CPAP, and you put in an LMA to provide CPAP. In the ICU, I would apply a nasal or oronasal mask and do CPAP that way.

Hagberg: I think one of the advantages for LMA is easy access for reintubation. So we do tend to use it with fiberoptic visualization of the vocal cords when we remove it, and then it's easy to re-insert and re-intubate, if necessary. So if you need immediate re-intubation, that's a little different. I think that's where it really comes into play. Some patients do well with it because it stents the adipose tissue open. Usually, the tongue can fall back and cause obstruction, but sitting the patient up with that LMA in really keeps the adipose tissue a little bit more open, and the patients tolerate it very well. But we haven't performed a study looking at those with versus those without and complications and re-intubation rates.

Hess: A common reason why we do not extubate patients in the ICU is control of secretions. It's not clear to me how the LMA might help.

Hagberg: Again, it's more about visualization as you remove a tube, so as you're bringing the tube out, you get to see if there are secretions accumulating and so forth. What the LMA tends to do is keep secretions from getting down to the glottis. When we remove the LMA, we often don't de- flate it, bringing the secretions out as we're coming out with the device.

Hess: In patients where we're debating whether to extubate or not, perhaps we should try that.

Hagberg: Yes, put the LMA behind it. In the OR, the exchange I showed was a craniotomy, where you don't want a lot of coughing or bucking on the tube. So we end up getting them breathing on the tube, remove the tube, and you can do a deep extubation or awake extubation and leave the LMA in place, either way. Sometimes with patients after thyroid surgery, we want to look at the function of the vocal cords, so we'll perform staged extubation using the LMA as a bridge. Regarding the LMA, you can apply CPAP just as you can with other devices, but I think the ability to easily re-intubate is significant, as well as preventing secretions from going forward, possibly causing laryngospasm.

Ramachandran: A couple comments about OSA and NIV. A study showed that use of Boussignac CPAP in morbidly obese patients helps prevent significant desaturation after extubation if applied immediately after extubation with a face mask. Mokhlesi et al in the last few months have shown some interesting data for sleep apneics; risk of re-intubation is 3-5 times greater than with non-sleep apneics using the Nationwide Inpatient Sample. They showed that their mortality rates are significantly lower than those patients who developed respiratory failure without SDB [sleep-disordered breathing], and the cost of care is also lower. This is really surprising. So their acute need for postoperative airway intervention is increased, but their overall respiratory risk is actually lower. So I think the sleep apnea story is a little nuanced; I don't think it's as simple as we think it is. Finally, I did a retrospective analysis ${ }^{3}$ on more than 1,000 cases. We observed 8 instances of pneumothoraces; I wasn't expect- 
ing that when I reviewed our cases. We also had a very high failure rate of tube exchange in the scenarios you described. The failure rate of re-intubation was close to $10 \%$ overall for tube change, particularly with the double-lumen tube, but in patients in whom we left it for various periods of time after surgery, the failure rate for re-intubation was $20 \%$ in our population. You did mention the cautions in the use of airway exchange catheters, and I think there are some patient safety considerations as well that are probably paramount.

Hagberg: Definitely before you use an airway exchange catheter either for re-intubation or for oxygenation, you should confirm that you are indeed in the trachea. That's one of the most important items to remember in its use, so you'll have more chance of success. I don't know if you mentioned in your study that when you're going to use it for re-intubation or oxygenation/ventilation, that you confirm its proper placement. I think that's one of the most important things to ascertain: its depth of placement and also proper placement in the trachea. A lot of times, they're inadvertently removed or in the wrong place. There are reports of gastric rupture with use of $\mathrm{O}_{2}$ insufflation through this device, even just a little bit of $\mathrm{O}_{2}$. I tend to not use it for oxygenation unless I absolutely need it for ventilation. I think you're absolutely right; jet ventilation in and of itself is a tricky technique. Most of us in this room don't do this every day, and it's fraught with complications. The provider needs to know what they're doing, if it's the right patient, and do you have the right equipment, a lot of different things to consider with more invasive techniques.

Ramachandran: The outer diameter in the Cook air exchange catheter and ETT [endotracheal tube] could be one of the reasons why re-intubation is difficult. A patient in respiratory distress is going to be less likely to accept a mouth-fitting tube in that scenario.

Hagberg: One thing that I really recommend when using these airway exchange catheters is that you perform laryngoscopy while you're doing the procedure. I had one just yesterday: a very difficult airway, it turned out. We ended up using the McGrath video laryngoscope to visualize the glottis since we saw a grade 3 view with DL [direct laryngoscopy]. The VL [video laryngoscope] just kept the tongue out of the way during the exchange because we first put a single lumen in and then changed it over to the double-lumen tube. I think it's a very good point to use laryngoscopy, either direct or video, as you're bringing a tube over a tube changer.

Blank: I wanted to ask Krish [Ramachandran], Carin, or any of the other panelists: have you used the newer Cook flexible tip exchanger?

Hagberg: I performed the previously mentioned exchange with that one because it's extra firm and longer. At first we tried the pediatric one because it was in the room, but it didn't work. I used the extra firm with the McGrath angulated blade, and that combination worked well.

Blank: Are there any objective data suggesting that it's safer regarding the incidence of pneumothoraces you referred to?

Ramachandran: We haven't changed our supply. I think it does have to do with the point that Dr Hagberg was making, which is that it's difficult to make sure you're maintaining the depth. It's very difficult. The friction of these different tubes is variable; lubricating them is fraught because then you lose control. It's a bad situation, it's a difficult airway, and you're trying your best to get back in. I don't think there are any easy ways. Material improvement might be the way forward. If we can create airway exchange catheters with extremely low friction, maybe it's going to be easier.

Hagberg: You're right: the diameter of the exchange catheter related to the tube diameter is very important. That's why you use a larger Cook catheter on a known tube exchange, and when it's a trial extubation, I tend to use the smaller diameter catheter.

Blank: With regard to CPAP postoperatively, a number of potential benefits have been identified. From a cardiorespiratory standpoint, we know that it can help improve LV systolic function. Obviously for OSA patients, it may be specifically indicated postoperatively. There's also a landmark study from Squadrone et $\mathrm{al}^{4}$ that showed that general surgery patients were postoperatively randomized to receive either CPAP or high-flow $\mathrm{O}_{2}$ via mask. There was a dramatic decrease in the risk of re-intubation in the CPAP group. They attributed this effect to atelectasis. We know that atelectasis is a big problem in the OR. A lot of anesthesiologists don't always appreciate it, but it occurs very quickly under general anesthesia and may be related to specific patient risk factors like obesity but is also related to the way we manage ventilation and oxygenation. CPAP may be indicated in a lot of these high risk patients.

Napolitano: One comment about a change that we made a couple of years ago in the patient population you described: known difficult airway, cuffleak test abnormal, we used to just wait another day, wait another day, and that really extends time of intubation and mechanical ventilation. Now, on the day of the abnormal cuffleak test, we will take a look via bronchoscopy and look at the larynx, and you can decide if it is edema and if the tube is too large. You can really tell and then make a plan and identify what 
needs to be done. I think that's a practice that's not used routinely.

Hagberg: You're right, it's not. I think it may be more that way in the future, especially with bronchoscopy; it's so easy to stick it in there.

Napolitano: Now it's part of our difficult airway algorithm.

Collins: Clearly, these patients are in step-down units or ICUs. In this regard, you showed a very relevant slide regarding physician and staff communication in what are often opentype units. It is probably logistically difficult to determine who makes that decision in such units. A classic situation would be the surgical team coming in and saying "let's extubate the patient today." I really appreciate that slide and think it is an important point to be made.

Hagberg: In my case, the one I described was a double-lumen tube, and I said, "We're going to leave this patient intubated and just change to a single-lumen tube," and the surgeon was hemming and hawing. The patient had to return for surgery the next day! That's communication, too; we need to know the plan, and if we don't all talk to each other, we're not going to know what to do. So often with handoffs in the ICUs, there's miscommunication or noncommunication.

\section{REFERENCES}

1. Apfelbaum JL, Hagberg CA, Caplan RA, Blitt CD, Connis RT, Nickinovich DG, et al. Practice guidelines for management of the difficult airway: an updated report by the American Society of Anesthesiologists Task Force on Management of the Difficult Airway. Anesthesiology 2013;118(2): 251-270.

2. Difficult Airway Society Extubation Guidelines Group, Popat M, Mitchell V, Dravid R, Patel A, Swampillai C, Higgs A. Difficult Airway Society Guidelines for the management of tracheal extubation. Anaesthesia 2012;67(3):318-340.

3. McLean S, Lanam CR, Benedict W, Kirkpatrick N, Kheterpal S, Ramachandran SK. Airway exchange failure and complications with the use of the Cook airway exchange catheter: a single center cohort study of 1,177 patients. Anesth Analg 2013;117(6): 1325-1327.

4. Squadrone V, Coha M, Cerutti E, Schellino MM, Biolino P, Occella P, et al. Continuous positive airway pressure for treatment of postoperative hypoxemia: a randomized controlled trial. JAMA 2005;293(5):589595. 